\title{
РУССКИЙ ЯЗЫК В КОНТРАСТИВНОМ АСПЕКТЕ - ВЗГЛЯД СО СТОРОНЫ КОРПУСА РУН
}

\author{
АтлЕ ГрёНН и ОЛЬГА КЛОНОВА \\ Университет Осло и Мурманский гуманитарный институт
}

Мы представляем третью, русскоязычную, часть материалов конференции «Русский язык в контрастивном аспекте», проведенной в Осло в сентябре 2009 года. Эта параллельная публикация первых двух частей на английском и третьей - на русском языке отвечает духу самой конференции и всего проекта РуН. Ключевая фраза проекта, конференции, сборника и настоящего введения - параллельный корпус в сопоставительной лингвистике.

\section{[1] СОПОСТАВИТЕЛЬНАЯ ЛИНГВИСТИКА И ПРОЕКт РУН}

В основе проекта РуН (2008-2010) лежит идея о том, что с помощью контрастивной лингвистики мы можем навести мосты над пропастью, которая, к сожалению, еще существует между наукой и высшим образованием в сфере обучения иностранным языкам, и, таким образом, приблизить эти два направления друг к другу. В нашем случае, в Университете Осло, мы хотели создать новую среду обучения для лучших студентов, изучающих русский язык, среду, которая была бы напрямую связана с современными лингвистическими исследованиями самого высокого уровня.

Для этого было предпринято следующее. Был установлен контакт с Мурманским гуманитарным институтом, где норвежский язык преподается как второй иностранный. Это является большим преимуществом с точки зрения проекта, учитывая тесные связи между Мурманском и Норвегией, особенно северными ее районами. Настоящая часть материалов конференции представляет отдельные результаты этого сотрудничества - статьи О. Клоновой, Т. Мелентьевой и О. Яныгиной, специалистов в обучении иностранному языку и активных участников проекта. Они, а также Г. Смирнова, вели занятия по русскому языку в Университете Осло, разрабатывая новые курсы по русскому языку для наших студентов.

\section{[2] Корпус РуН}

Следующее, что необходимо было сделать для проекта РуН - найти общую платформу для норвежских исследователей и студентов, изучающих русский язык, с одной стороны, и русских ученых и студентов, изучающих 
норвежский - с другой. Такой платформой и призван был стать руссконорвежский параллельный корпус РуН.

В Университете Осло, на кафедре европейских языков существует давняя традиция, восходящая к ныне покойному Стигу Йохансону, традиция создания параллельных корпусов, т.е. баз текстов (оригинальных и переводных), сопоставленных на уровне предложения. Таков, например, многоязычный корпус OMC (the Oslo Multilingual Corpora), в котором собраны тексты на норвежском, английском, немецком и французском языках.

Корпус РуН - это параллельный корпус, состоящий, в основном, из норвежских и русских текстов; большинство текстов представлено также и в переводах на английский язык. Тексты в корпусе РуН сопоставлены на уровне предложения, каждое слово снабжено морфологической разметкой. На декабрь 2010 года корпус включал примерно 2 миллиона слов на норвежском языке, 2 миллиона слов на русском и 1 миллион слов на английском. Сейчас корпус расширяется за счет текстов на болгарском, боснийском / хорватском / сербском, польском, итальянском и французском, немецком и шведском языках, в результате чего он стал по-настоящему многоязычным и получил название РуН-Евро. Просмотр текстов доступен в режиме он-лайн (см. RuN-Euro Corpus).

Корпусы РуН-Евро и ОМС построены на общем интерфейсе Глосса, разработанном текстовой лабораторией Университета Осло. С помощью этой системы результаты поиска могут быть различным образом обработаны, что упрощает статистический анализ данных. В корпусе РуН-Евро содержатся, в основном, современные художественные тексты, поэтому он не может считаться репрезентативным. Однако параметры поиска в Глоссе позволяют упорядочивать по дате публикации, автору и жанру; именно поэтому мы не рассматриваем как серьезную проблему тот факт, что корпус в целом не является в полной мере репрезентативным.

\section{[2.1] Почему параллельньй корпус?}

Сбор материала, несомненно, самое слабое место многих теоретических работ по синтаксису и семантике. Нечасто можно встретить работу, сочетающую в себе строгую теоретическую базу и тщательный анализ большого объема материала. В теоретической лингвистике доминирует убеждение, что реальный языковой материал настолько сложен, что нужно его упрощать вследствие чего появляются придуманные «игрушечные» предложения. Существует опасность, однако, что при таком упрощении теряются важные наблюдения над функционированием естественного языка.

По сравнению с традиционными методами, поиск материала в параллельном корпусе может быть очень увлекательным занятием для исследователя, и, в конечном счете, результаты будут интереснее и для читателя. Корпус 
предоставляет доступ к аутентичному языковому материалу, качественной литературе, художественным переводам искомых текстов. Доступ к такому материалу особенно ценен для лингвиста, не владеющего исследуемым языком как родным (а в сопоставительных штудиях большинство ученых не могут полностью полагаться на свою интуицию, если только они не из тех редких билингвов, кому повезло со знанием языков).

Нас также не должен смущать тот факт, что языки в целом, и, в частности, сопоставленные в параллельном корпусе тексты, иногда могут существенно отличаться. Во-первых, при достаточном объеме материала в корпусе все отклонения и «неудобные» переводы будут исключены как статистически незначимые. Во-вторых, корпус даст нам представление о частотности / встречаемости того или иного лингвистического явления как внутри языка, так и в сопоставлении с данными других языков. Если в языке структура $x$ встречается в 10 раз чаще, чем структура $y$, мы, как лингвисты, должны найти объяснение этому отличию. Данные, собранные таким способом, могут быть обработаны отличными по разным параметрам методами, включая статистические, многие из которых еще только предстоит включить в арсенал лингвистических средств. Можно ожидать, что это «столкновение» между традиционной теоретической лингвистикой и статистическими методами приведет к любопытным выводам.

Сейчас в сопоставительной лингвистике в условиях ограниченного доступа к хорошим параллельным корпусам приходится использовать другие традиционные источники материала (одноязычные корпусы, поисковые системы, такие как Google или Яндекс, а также информанты, интроспекция и т.д.). Основной недостаток параллельных корпусов, существующих на сегодняшний день, - это их скромные размеры по сравнению с одноязычными корпусами, в которых могут насчитываться сотни миллионов слов. Причина этого недостатка очевидна: собрать параллельный корпус во всех отношениях гораздо сложнее, чем одноязычный. Поэтому исследователям в контрастивной лингвистике всегда будет казаться, что их корпус ограничен. Но это не повод, чтобы сдаваться. Упорно работая, можно все больше расширять базу корпуса.

Хотя параллельный корпус и не заменит традиционные методы, например, одноязычные корпусы, интроспекцию и работу с информантами, но, тем не менее, создавая достаточно большие корпуса, мы разрабатываем новые стандарты в контрастивной лингвистике. Некоторые явления, о которых шла речь и на нашей конференции в Осло, встречаются так часто, что мы можем уже сейчас эмпирическим путем проверить гипотезы, присутствующие, скажем, в статьях этого сборника. 


\section{[2.2] Применение корпуса РуН}

Параллельные корпусы, такие как корпус РуН, могут быть интересны исследователям в разных областях сопоставительной лингвистики - от теоретической и компьютерной до лексикографии, обучения иностранному языку и теории перевода. В дальнейшем наш корпус также будет использован для создания дидактических материалов, например, интерактивного пособия по переводу.

Кроме того, корпус активно используется студентами Университета Осло, изучающими русский язык, и студентами в Мурманске, изучающими норвежский язык, в связи с различными языковыми курсами, разработанными в рамках проекта РуН. Так, были написаны студенческие исследовательские работы на разные темы, например: приставки совершенного вида (способы действия); относительное время; неопределенные местоимения; дискурсивные частицы; лексическая семантика; стратегии перевода и т.д.

Таким образом, преимущества работы с корпусом очевидны: мы можем сочетать качественные лингвистические исследования и обучение иностранному языку на высоком уровне.

\section{[3] РУССКАЯ ЧАСТЬ СБОРНИКА}

Конференция «Русский язык в контрастивном аспекте», проведенная в Осло в 2009 году, была местом встречи всех участников проекта и многих ведущих ученых в сопоставительной лингвистике и русистике. В этом разделе представлены статьи русскоязычной части сборника с точки зрения корпуса РуН, из которого взято большинство нижеследующих примеров.

\section{[3.1] Семантика и синтаксис}

Начнем с двух статей, написанных в духе западной семантики. Автором первой является Елена Викторовна Падучева, ведущий представитель Московской семантической школы на протяжении уже полувека. Ее заслуги хорошо известны всем, кто знаком с лингвистикой в России. Для просмотра ее лекции перейдите по ссылке на домашней странице проекта РуН.

Статья Е. В. Падучевой, объединяющая западную (Вендлер, Картуннен) и русскую традиции, посвящена сочетаемости фактивных глаголов и косвенных вопросов. На примерах из корпуса можно видеть, что русский глагол «гадать» и английский «guess» могут подчинять косвенные вопросы:

(1) $\mathrm{P}$ это, конечно, кто-нибудь из пациентов подбросил котенка, что это нередко бывает у профессоров. [...] Стали думать и гадать, кто бы мог подбросить. (М. Булгаков, «Мастер и Маргарита») 
A it was, of course, one of the patients who had abandoned the kitten, as happens not infrequently to professors. [...] They started thinking and guessing who might have abandoned it.

$\mathrm{H}$ det måtte være en av pasientene som hadde lurt kattungen inn, at den slags ofte hendte med professorer. [...] De begynte å tenke etter og gjette hvem som kunne være kommet med den.

Но то, что разрешено в одном языке, не может быть автоматически перенесено в другой язык, как показывает следующий пример из статьи Падучевой (из устной речи иностранного аспиранта):

(2) Так вам восемьдесят лет? А мы догадывались, что шестьдесят.

(Следует говорить - предполагали, думали.)

Как пишет Падучева, легко себе представить потенциальное существование нефактивного догадываться. Такого глагола нет в русском языке, хотя он вполне мыслим.

Вторая статья из вышеназванных принадлежит почетному профессору Гансу Роберту Мелигу, одному из самых влиятельных исследователей категории вида в русском языке среди славистов во всем мире. Профессор Мелиг рассматривает границы грамматичности, и потому использует придуманные примеры. Корпус же предоставляет нам следующие примеры:

(3) $\mathrm{P}$ Ей жаль будить его. - Сашенька, - говорит она печально, - вставай, голубчик! В гимназию пора. Он встает, одевается, молится богу, потом садится чай пить; выпивает три стакана чаю и съедает два больших бублика и полфранцузского хлеба с маслом.

(А. Чехов, «Душечка»)

A She was sorry to wake him. "Sashenka", she would say mournfully, "get up, darling. It's time for school." He would get up, dress and say his prayers, and then sit down to breakfast, drink three glasses of tea, and eat two large cracknels and a half a buttered roll.

H Hun synes det er synd å vekke ham. - Sasja, sier hun trist, - nå må du stå opp, elsklingen min! Du må gå på skolen. Han står opp, kler på seg, ber til Gud, setter seg for å drikke te. Han drikker tre glass te og spiser to store horn og et franskbrød med smør på.

Предложение (3Р) действительно вызывает некоторые вопросы - глаголы несовершенного вида «выпивает» и «съедает» сочетаются с фразами количества, что приводит к парадоксу несовершенного вида: если событие рассматривается в его развитии (несовершенный вид), то как можно узнать о том, что Саша выпивает три стакана чая и съедает два бублика? Мелиг рассматривает похожие примеры в своей работе, но в случае (3Р) объяснение гораздо проще: 
настоящее время в этом примере - это нарративное настоящее в прошедшем, поэтому, согласно критерию Маслова, глагол несовершенного вида используется как совершенный (выпил, съел).

Мелиг также указывает на то, что несовершенный вид чаще используется с накопителем в тех случаях, когда накопитель определен с помощью местоимения, например, свой - ср. доживал свои дни и ??доживал дни:

(4) Р Ведра пустели быстро, и кавалеристы из разных взводов по очереди отправлялись за водой в балку под горой, где в жидкой тени тощих тутовых деревьев доживал свои дни на этой дьявольской жаре мутноватый ручей. (М. Булгаков, «Мастер и Маргарита»)

A The buckets were quickly emptied, and cavalrymen from different squads took turns going to fetch water in the gully below the hill, where in the thin shade of spindly mulberries a muddy brook was living out its last days in the devilish heat.

Статья Ольги Клоновой (Мурманск) представляет собой попытку объединить корпусные данные и традиционный для русской лингвистики подход к синтаксису в целях сопоставления безличных конструкций в русском и норвежском языках. Тема статьи идеально подходит для корпусных исследований. Сравнивая употребление безличных предложений в русском и норвежском языках, автор приходит к выводу, что в обоих языках этот тип конструкций очень часто соотносится с определенными группами глаголов, например, с так называемыми «атмосферными глаголами». Более того, норвежский язык (в отличие от русского) практически всегда предпочитает безличные конструкции с формальным det, когда речь идет об атмосферных явлениях:

(5) Р Уже рано смеркалось. (А. Чехов, «Ионыч»)

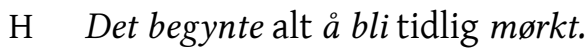

A It was already beginning to get dark early.

(6) Р Под утро поднялся ветер, и у Медеи сильно разболелась голова. (Л. Улицкая, «Медея и ее дети»)

$\mathrm{H} \quad$ Utpå morgenkvisten begynte det å blåse, og Medea fikk kraftig hodepine. A A wind blew up toward morning, and Medea developed a severe headache.

С помощью корпуса можно не только сопоставлять языки, но и составлять, например, списки глаголов (оборотов, фраз) и глоссарии, необходимые в переводческой практике - в нашем случае, это список вариантов перевода безличных конструкций, не имеющих прямых словарных эквивалентов в языке перевода. 


\section{[4] «МАЛЕНЬКИЕ СЛОВА»}

Для лексикографических целей большой параллельный корпус также может быть весьма полезен, возможно, он совершит переворот в лексикографии. Возьмем, например, слово «однако», которому посвящена статья Марии Смирновой: можно легко установить на основании корпуса РуН, что это слово переводится на английский язык с помощью трех лексем: however, but, though. Мы можем, однако, пойти дальше: параллельный корпус может дать количественную информацию о переводе этого слова, отсутствующую в традиционных словарях:

- однако - however: $25 \%$

- однако - but: $31 \%$

- однако - though: $16 \%$

Однако хороший параллельный корпус может предоставить нам и конкретные примеры для иллюстрации различных употреблений однако - например, эмоциональное использование этого слова:

(7) Р - Сколько хлопот, однако! (А. Чехов, «Ионыч»)

A What a lot of trouble, though!

H Også så mye mas det var!

(8) Р Как ты измок, однако! (Л. Толстой, «Анна Каренина»)

A But how wet you are!

$\mathrm{H} \quad$ Men du er jo helt gjennomvåt!

(9) Р - Какой ты, однако, ретроград! (Л. Толстой, «Анна Каренина»)

A What a reactionist you are, really!

$\mathrm{H}$ Men for en bakstrever du er!

Последний пример (9P) интересен тем, что он дает нам вариант перевода «однако», незафиксированный в словаре - really.

М. Смирнова использует данные из немецко-русского параллельного корпуса НКРЯ и рассматривает различные примеры использования и значения лексемы «однако», которые проявляются в переводах на немецкий язык. В случае такого рода лексических единиц параллельный корпус может быть полезен как в практических целей для создания двуязычных словарей, так и для теоретических сопоставительных исследований.

Алексей Чернышев в своей работе сопоставляет русский предлог «до» и английский “to” на основе одноязычных корпусов, но данные явления было бы чрезвычайно интересно рассмотреть и на примерах из параллельного корпуса, что не вызывает никаких затруднений: 
(10) $\quad$ Р $\quad$ Вы педагог до мозга костей. (А. Чехов, «Учитель»)

A You are a schoolmaster to the marrow of your bones.

H De er en pedagog av Guds nåde.

(11) $\mathrm{P}$ Ванька добежал до первого почтового ящика. (А. Чехов, «Ванька»)

A Vanka ran to the nearest post-box.

$\mathrm{H} \quad$ Vanka løp bort til den nærmeste postkassen.

(12) P Эти загадки до нас не дошли. (В. Пелевин, «Поколение П»)

A These riddles have not come down to us.

$\mathrm{H} \quad$ Disse gåtene er ikke overlevert til oss.

Эти примеры представляют собой перевод с русского языка; очевидно, что для полноты картины стоит рассмотреть примеры обратного перевода с английского на русский:

(13) A It frightens me to death. (R. Dahl "Kiss Kiss")

P Оно меня пугает до смерти.

Безусловно, это только лишь начальный этап. Для того чтобы показать, что, по мысли автора, разные картины мира обуславливают разные модели употребления предлогов, необходимо рассмотреть случаи несоответствия «до» и "tо" в оригинале и в переводе. Это легко осуществить с помощью параллельного корпуса, и мы не будем здесь прибегать к этим простым упражнениям.

Вместо этого, хотелось бы отметить еще одну возможность, которую предоставляет многоязычный корпус: анализ может включать более двух языков, ср., например, предлог «до» в русском, сербском и болгарском, представленный в следующем примере из корпуса РуН-Евро:

(14) A He tried to increase the tension, but the line had been taut up to the very edge of the breaking point since he had hooked the fish.

(E. Hemingway, "The Old Man and the Sea")

P Он попытался натянуть бечеву потуже, но с тех пор, как он поймал рыбу, леса и так была натянута до отказа.

Б Той се опита да дръпне по-силно, но откакто бе уловил рибата, въжето бе все така опънато, до скъсване.

C Он покуша да појача затегнутост али конопац, откако је риба загризла удицу, није био никада као сада напет до својих крај их граница.

\section{[4.1] Лексикон}

Изучение лексики очень популярно в русской лингвистике (см. тж. часть 2 материалов конференции, большинство статей которой посвящено именно 
лексикону). В статье Тамары Лёнгренн речь идет о глаголе «вязать» в русском, шведском и норвежском языках - отличия, о которых пишет автор, можно найти и в корпусе. Вот несколько примеров, лишь поверхностно иллюстрирующих данную проблему:

(15) Р Она вязала на заказчиков свитера, кормила семью.

(Л. Улицкая, «Медея и ее дети»)

$\mathrm{H} \quad$ Hun strikket gensere på bestilling og forsørget familien med det.

A She knitted sweaters to order, taking over as the breadwinner.

(16) Р Она держала в руках вязанье, но не вязала.

(Л. Толстой, «Анна Каренина»)

$\mathrm{H} \quad$ Hun holdt hekletøyet i hendene, men heklet ikke.

A She held the work in her hands, but did not crochet.

(17) Р - тут вбежали люди, стали меня вязать и повели в тюрьму.

(М. Булгаков, «Мастер и Маргарита»)

$\mathrm{H} \quad$ for her kom det folk styrtende inn, begynte å binde meg og tok meg med til fengselet.

A Here men ran in, bound me, and took me away to prison.

Татьяна Мелентьева, преподаватель норвежского языка (Мурманск), рассматривает лингвокультурологический аспект русской и норвежской лексики. Следующий пример иллюстрирует два явления, о которых упоминает автор: во-первых, слово «душа» в русском языке «богаче» на коннотации, чем в норвежском, во-вторых, слово “likestilling” гораздо глубже укоренилось в норвежской лингвокультуре, чем его русский эквивалент - в русской:

(18) Р Весело ухая, она отъезжала в направлении моря на джипе в обнимку с девицами, которые явно чихать хотели на женское равноправие (когда приходится тесно общаться с обезьянами, лучше просто не думать о подобных вещах, потому что равноправие и неравноправие будут одинаково тяжелы для души).

(В. Пелевин, «Поколение П»)

$\mathrm{H}$ Med lystige stønn kjørte den i en jeep i retning havet, omfavnet av ungjenter som gav blaffen i kvinnefrigjøring. (I intim omgang med aper er det best ikke å tenke på slikt, for likestilling er like vanskelig for sjelen som mangel på likestilling.)

Идиомы в двуязычных словарях, о которых идет речь в статьях Анастасии Козеренко и Елены Бертемет, очевидно, представляют собой один из тех аспектов, для которых в будущем большие параллельные и многоязычные корпуса могут стать уникальным источником материала. Уже сейчас благодаря им можно получить несомненно интересные данные; сравним для примера 
переводы выражения «медвежья услуга» и увидим, что эта единица встречается в норвежском оригинале, переводах на русский и немецкий язык, но не в переводах на английский и французский:

(19) $\mathrm{H}$ han kanskje gjorde sin beste venn en bjørnetjeneste ved å gi ham Dina. (H. Wassmo, "Dinas bok")

P выдавая Дину за своего лучшего друга, он оказывает тому медвежью услугу.

A he might be doing his best friend an unintentional disservice by giving Dina to him.

$\Phi \quad$ il rendait peut-être un mauvais service à son meilleur ami en lui donnant Dina.

$\mathrm{H}$ er seinem besten Freund vielleicht einen Bärendienst erwies, er ihm Dina gab.

\section{[5] ОТ ОТДЕЛЬНЫХ СЛОВ К ПЕРЕВОДУ ТЕКСТА}

Сборник завершают две статьи, основной темой которых является перевод художественных текстов.

Ольга Яныгина (Мурманск) в своей статье принимает во внимание не столько лингвистические преимущества, которые дает нам параллельный корпус, сколько художественную ценность текста. О. Яныгина анализирует перевод на русский язык романа Э. Лу «Наивно. Супер» (текст которого есть в корпусе РуН) с точки зрения передачи имплицитных эмотивных компонентов. ${ }^{1}$ Как пишет автор, «в текстах [Э. Лу] используется широкий круг эмоционально-оценочных номинаций, активно пополняемый авторскими окказиональными обозначениями»:

(20) H Jeg skulle ta min bror, den jævelen. (E. Loe "Naiv. Super")

P Уж я покажу братику, сейчас он у меня попляшет, черт его дери!

Р Я покажу моему брату, гаду этакому.

Тем не менее, в русском переводе эмоции выражаются гораздо сильнее: «эмоционально-экспрессивная частица «уж», которая придает большую живость и эмоциональность высказыванию, «сейчас он у меня попляшет», «черт его дери!» - все эти лексические средства передают, пожалуй, даже излишне эмоционально на русском языке» описываемую ситуацию из жизни героя.

В рамках проекта РуН были выполнены переводы отдельных отрывков романа Э. Лу для интерактивного пособия по переводу с русского на норвежский язык. Стиль этих переводов (выполненных разными носителями русского языка, не являющимися профессиональными переводчиками) несколько от-

${ }^{1}$ В 2008 году О. Яныгина также читала лекции в Университете Осло - в рамках проекта РуН - о роли имплицитной информации в русском и английском / норвежском текстах. 
личается от перевода, анализируемого О. Яныгиной: в них не так широко представлена эмоциональная составляющая, и они более близки тексту оригинала (как отмечает автор статьи), что вызвано, в первую очередь, их обучающей направленностью. О. Яныгина в своей статье приводит один из них, и на его фоне становится очевиднее рассматриваемая особенность перевода, выполненного профессионально: два перевода на русский язык значительно отличаются друг от друга по эмотивным составляющим. Это можно наблюдать как в примере (20), так и в других примерах:

(21) H Min bror hadde blitt røver og nå lå den røde kulen min under den store busken. Min bror sto naturligvis og lo. (E. Loe "Naiv. Super")

P Пришел черед брата разбойничать на площадке, и вот уже мой красный шар закатился в гущу разросшегося куста. А братец, конечно, стоит себе и смеется.

Р Мой брат стал разбойником и теперь мой красный шар лежал 8 большом кусте. Мой брат, конечно же, стоял и смеялся.

В этом случае первый из представленных переводов на русский язык изобилует разговорной лексикой, более эмоционально насыщенной - $n p u$ шел черед, братец, стоит себе и смеется. Второй, напротив, эмоционально сдержаннее и в этом, как и в подборе слов и синтаксисе, больше отвечает «букве» романа. Профессиональный (художественный) перевод, скорее, соответствует его «духу».

Таким образом, по словам автора статьи, «доминирующим способом актуализации эмпатемы при переводе с норвежского языка на русский, как правило, является экспликация как метод уточнения смысла той или иной эмпатемы.» Это объясняется культурными и языковыми различиями и приводит к тому, что эмоциональность, выраженная имплицитно в оригинале, в (художественных) переводах на русский язык передается эксплицитно.

Статья Игоря Кудряшова о «Лолите» В. Набокова завершает сборник. Этот роман уникален в том плане, что автор одновременно является и переводчиком. И. Кудряшов сравнивает выражение времени в английском и русском текстах, акцентируя внимание не столько на собственно лингвистических вопросах, сколько на особенностях концепта времени в романе. Автор затрагивает несколько вопросов, которые требуют более масштабного анализа лингвистического и стилистического уровней.

Рассмотрим только один пример из этой статьи: ${ }^{2}$

\footnotetext{
${ }^{2}$ Тексты Набокова (будут) добавлены в корпус РуН-Евро на многих языках (благодарим Бориса Орехова (Уфа), участника проекта РуН, который работает над созданием корпуса всех набоковских текстов).
} 
(22) A Another time a red-haired school girl hung over me in the metro, and a revelation of axillary russet I obtained remained in my blood for weeks (V. Nabokov "Lolita")

P Другой раз рыжеволосая школьница повисла надо мною в вагоне метро, и оранжевый пушок у нее под мышкой был откровением, оставшимся на много недель у меня в крови

Анализируя этот и другие примеры, автор отмечает, что «в русскоязычном переводе романа «Лолита» темпоральные пропозиции передают большую растяженность временного промежутка событий, субъективное время Гумберта оказывается более «растянутым» в объективном времени, чем в оригинале романа». Эти различия в переживании времени главным героем И. Кудряшов связывает с особенностями русской и английской картин мира.

\section{ПРИЗНАТЕЛЬНОСТЬ}

Редакторы третьей части материалов конференции - Атле Грённ и Ольга Клонова, редакторы первых двух частей - Атле Грённ и Ирена Мариянович.

Выражаем благодарность участникам конференции в Осло, авторам статей и рецензентам, Марине Можаровской за чтение корректуры. Отдельно отметим нетривиальную техническую сторону работы с материалами конференции. Перевод текстов статей из программы Word в $\mathrm{LT}_{\mathrm{E}} \mathrm{X}$ был выполнен Владиславом Дорохиным, Атле Грённом и Павлом Иосадом.

Конференция «Русский язык в контрастивном аспекте» была организована проектом РуН (2008-2010), финансируемым Норвежским центром международного сотрудничества в области высшего образования (SIU).

\section{АдРесА АВТоров}

Atle Grønn

Department of Literature, Area Studies and European Languages

University of Oslo

Norway

atle.gronn@ilos.uio.no

Ольга Клонова

Мурманский гуманитарный институт

Кафедра германских языков и филологии

Мира 10-205, Мурманск

Россия

olgaklonova@hotmail.com 